\title{
Survival in colon and rectal cancers in Finland and Sweden through 50 years
}

\author{
Kari Hemminki (D) , ,2 Asta Försti, ${ }^{3,4}$ Akseli Hemminki ${ }^{5,6}$
}

\begin{abstract}
To cite: Hemminki K, Försti A, Hemminki A. Survival in colon and rectal cancers in Finland and Sweden through 50 years. BMJ Open Gastro 2021;8:e000644. doi:10.1136/ bmjgast-2021-000644
\end{abstract}

\section{- Additional supplemental} material is published online only. To view, please visit the journal online (http://dx.doi. org/10.1136/bmjgast-2021000644).

Received 9 March 2021 Accepted 11 April 2021

\section{Check for updates}

(c) Author(s) (or their employer(s)) 2021. Re-use permitted under CC BY-NC. No commercial re-use. See rights and permissions. Published by BMJ.

${ }^{1}$ Biomedical Center, Faculty of Medicine and Biomedical Center in Pilsen, Charles University in Prague, Pilsen, Czech Republic

${ }^{2}$ Division of Cancer Epidemiology, German Cancer Research Center (DKFZ), Im Neuenheimer Feld 580, Heidelberg, BadenWürttemberg, Germany ${ }^{3}$ Hopp Children's Cancer Center (KiTZ), Heidelberg, Germany ${ }^{4}$ Division of Pediatric Neurooncology, German Cancer Research Center (DKFZ), German Cancer Consortium (DKTK), Heidelberg, Germany ${ }^{5}$ Cancer Gene Therapy Group, Helsingin yliopisto, Helsinki, Uusimaa, Finland

${ }^{6}$ Comprehensive Cancer Center, Helsingin yliopistollinen Keskussairaala, Helsinki, Uusimaa, Finland

Correspondence to Dr Kari Hemminki; k.hemminki@dkfz.de

\section{ABSTRACT}

Objectives Global survival studies have shown favourable development in colon and rectal cancers but few studies have considered extended periods or covered populations for which medical care is essentially free of charge. Design We analysed colon and rectal cancer survival in Finland and Sweden over a 50-year period (1967-2016) using data from the Nordcan database. In addition to the standard 1-year and 5-year survival rates, we calculated the difference between these as a novel measure of how well survival was maintained between years 1 and 5 . Results Relative 1-year and 5-year survival rates have developed favourably without major shifts for men and women in both countries. For Finnish men, 1-year survival in colon cancer increased from $50 \%$ to $82 \%$, and for rectal cancer from $62 \%$ to $85 \%$. The Swedish survival was a few per cent unit better for 1-year survival but for 5-year survival the results were equal. Survival of female patients for both cancers was somewhat better than survival in men through 50 years. Overall the survival gains were higher in the early compared with the late follow-up periods, and were the smallest in the last 10 years. The difference between 1-year and 5-year survival in colon cancer was essentially unchanged over the 50-year period while in rectal cancer there was a large improvement. Conclusions The gradual positive development in survival suggests a contribution by many small improvements rather than single breakthroughs. The improvement in 5-year survival in colon cancer was almost entirely driven by improvement in 1-year survival while in rectal cancer the positive development extended to survival past year 1 , probably due to successful curative treatments. The current challenges are to reinvigorate the apparently stalled positive development and to extend them to old patients. For colon cancer, survival gains need to be extended past year 1 of diagnosis.

\section{INTRODUCTION}

Incidence and mortality are common measures describing the population burden of disease (cancer) and they convey information on survival. ${ }^{1}$ Survival in many cancers has improved over the past years in the developed countries. ${ }^{2}$ Although the underlying data appear undisputed, the reasons for the favourable development have many interpretations. One of the early success stories was Hodgkin lymphoma for which the gains were ascribed to the use of risk-adapted therapies using intensive poly-chemotherapeutic
Summary box

What is already known about this subject?

- Although it is known that survival in colon and rectal cancers has increased the reasons are not well understood, as long-term trends in countries with free medical care have been lacking.

What are the new findings?

- The gradual positive development in survival over 50 years suggests a contribution by small improvements rather than single break-throughs. The improvement in 5-year survival in colon cancer was almost entirely driven by improvement in 1-year survival while in rectal cancer the positive development extended to survival past year 1 .

How might it impact on clinical practice in the foreseeable future?

- For colon cancer, patient care needs to be improved past year 1 of diagnosis. For rectal cancer, care of old patients need more focus.

regimens in combination with other modalities. $^{3}$ In childhood acute lymphoblastic leukaemia, the improvements were ascribed to treatment-related precise risk stratification, early assessment of minimal residual disease and supportive care. ${ }^{4}$ Success in testicular cancer care was ascribed to a rational utilisation of combination chemotherapy, and the integration of care involving medical and surgical specialties resulting in cure rates of over $90 \% .^{5}$ The key role of clinical randomised trials in selecting the optimal treatment is universally emphasised in enabling these success stories, but for many other cancers the 'real world' cure circumstances may be far from the selected patient populations and controlled treatment protocols of the clinical trials. Many survival studies cover relatively short periods which do not allow assessment of the survival experience over decenniums, which would be important to understand the factors influencing the 'real world' survival trends. ${ }^{26-8}$

Cancers of the colon and the rectum are the second in the global ranking of incident and fatal cases after lung cancer. ${ }^{9} 10$ These 
cancers are often considered jointly as 'colorectal cancer, CRC' as colon and rectal cancers share many biological features and risk factors. Yet some authors point out that the two cancers differ in their embryological origin and metastatic patterns, in addition to many therapy-related factors. ${ }^{112}$ The diagnostic and therapeutic principles for colon and rectal cancer have changed over the years as detailed in online supplemental material. We will discuss these in terms of the survival experience in Finland and Sweden over a period of 50 years. For a 'real world' experience, these two countries are examples of practically free-of-charge medical care to the population at large. The reason for selecting these two countries, and for example not all of the 5 Nordic Countries, is that the authors have first-hand knowledge about Finland and Sweden. Moreover, the extensive earlier literature between the Nordic cancer registries points out to large similarities, whereby data volume might distract from the findings. ${ }^{13}$ Sweden (population 10.2 million in 2019) has been internationally an example of high-level medical care and prosperous economy since the World War Two. The gross national product (GNP) per capita was US\$3460 in 1967 and it increased to US\$54370 in 2016; the healthcare share improved from $6.6 \%$ to $11.0 \%$ of GNP in the same period (www.macrotrends.net). GNP of Finland (population 5.5 million in 2019) was US\$2035 in 1967 and it increased to US\$43784 in 2016, with the related healthcare share increasing from $5.7 \%$ to $9.4 \%$ (www.macrotrends.net). With analysis of the incidence/ mortality/survival patterns in the Nordcan database, we try to understand factors underlying the improvements in survival in colon and rectal cancers over a 50-year period. However, as there is even current literature on incidence and mortality on CRC from Finland and Sweden, we report these data only in the supplement, in support of the survival analyses. ${ }^{10} 14$

\section{METHODS}

The data used originate from the Nordcan database which is a compilation of data from the Nordic cancer registries as described. ${ }^{15}$ These registries are presented in detail by Pukkala et al. ${ }^{16}$ The database can now be accessed at International Agency for Cancer (IARC) website (https://nordcan.iarc.fr/en/database\#bloc2). The analyses were conducted interchangeably at the IARC and the Nordcan sites (https://nordcan.iarc.fr/ en/database\#bloc2). The database combines rectal and anal cancers (in accordance with International Classification of Diseases version 7, ICD-7). We have no way of removing anal cancers but they constitute a tiny portion of all rectal and anal patients; for example, in 2016, $92.4 \%$ of these cancers were rectal cancers, $96.5 \%$ among men and $86.9 \%$ among women.

Coverage of cancers in the Finnish and Swedish cancer registries is generally considered high. ${ }^{16}$ The Swedish cancer registry does not consider cancers in death notifications and some $4 \%$ cases may be missed because of this; an overall comparison of various health records showed that the coverage was over $90 \% .{ }^{16}{ }^{17}$ Comparability of diagnostics of a 50-year period may be an issue. The Swedish cancer registry used ICD-7 from the start of registration in 1958 . When new codes have been taken to use, all diagnoses are additionally recoded in the ICD-7 system to maintain consistence. ${ }^{18}$ Finland uses a code conversion system to maintain consistency. In Finland and Sweden, the cause of death register is independent from cancer registration, and the smoothly declining mortality trends are another indication for consistency of diagnostics (online supplemental figure 1).

Data on the Finnish and Swedish patients were extracted from Nordcan where the follow-up was extended until death, emigration or loss of follow-up or to the end of 2016. For incidence and mortality data, the starting date was the earliest available, 1953 for Finland, 1960 for the Swedish incidence and 1952 for the mortality data. For age standardisation, the world standard population was used. In Nordcan, the tool for incidence and mortality analysis by period ('Time trends (Incidence/Mortality') were selected for analysis. Survival data for relative survival were available from 1967 onwards and the analysis was based on the cohort survival method for the first nine 5-year periods from 1964 to 2011, and a hybrid analysis combining period and cohort survival in the last period 2012-2016, as detailed. ${ }^{19} 20$ The hybrid method includes cases from the penultimate 5 -year period to allow for a 5 -year survival. ${ }^{21}$ Age groups $0-89$ were considered, and for age-standardisation the International Cancer Survival Standard was used. The Finnish and Swedish life tables were used to calculate the expected survival. Periodspecific survival analysis was executed with tool 'Table by country and period', and the results were compiled from the relevant analyses. For age group specific survival, no case numbers were available. We estimated significance of the survival difference for the youngest and oldest age groups by comparing to the $95 \%$ CIs of all individuals in the relevant period.

We calculated also a difference in survival per cent between year 1 and year 5 as a measure on how well survival is maintained between years 1 and 5 . A small difference indicates high survival between years 1 and 5 after diagnosis. This measure may be more concretely described by the complementary mortality, $\mathrm{X}=100 \%$-survival \%. Thus if 1-year mortality X is small (say $10 \%$ with $90 \%$ survival), and 5-year mortality is also small (say $20 \%$ with $80 \%$ survival) then mortality is low and survival is favourable in the interval between 1 and 5 years.

In graphic presentation, smoothing of data in 3-year intervals were used.

\section{RESULTS}

The Nordcan database included 0.49 million male and 0.48 million female cancers for Finland, and 1.01 million male and 0.94 million female cancers for Sweden, excluding non-melanoma skin cancer, for years 1967 to 


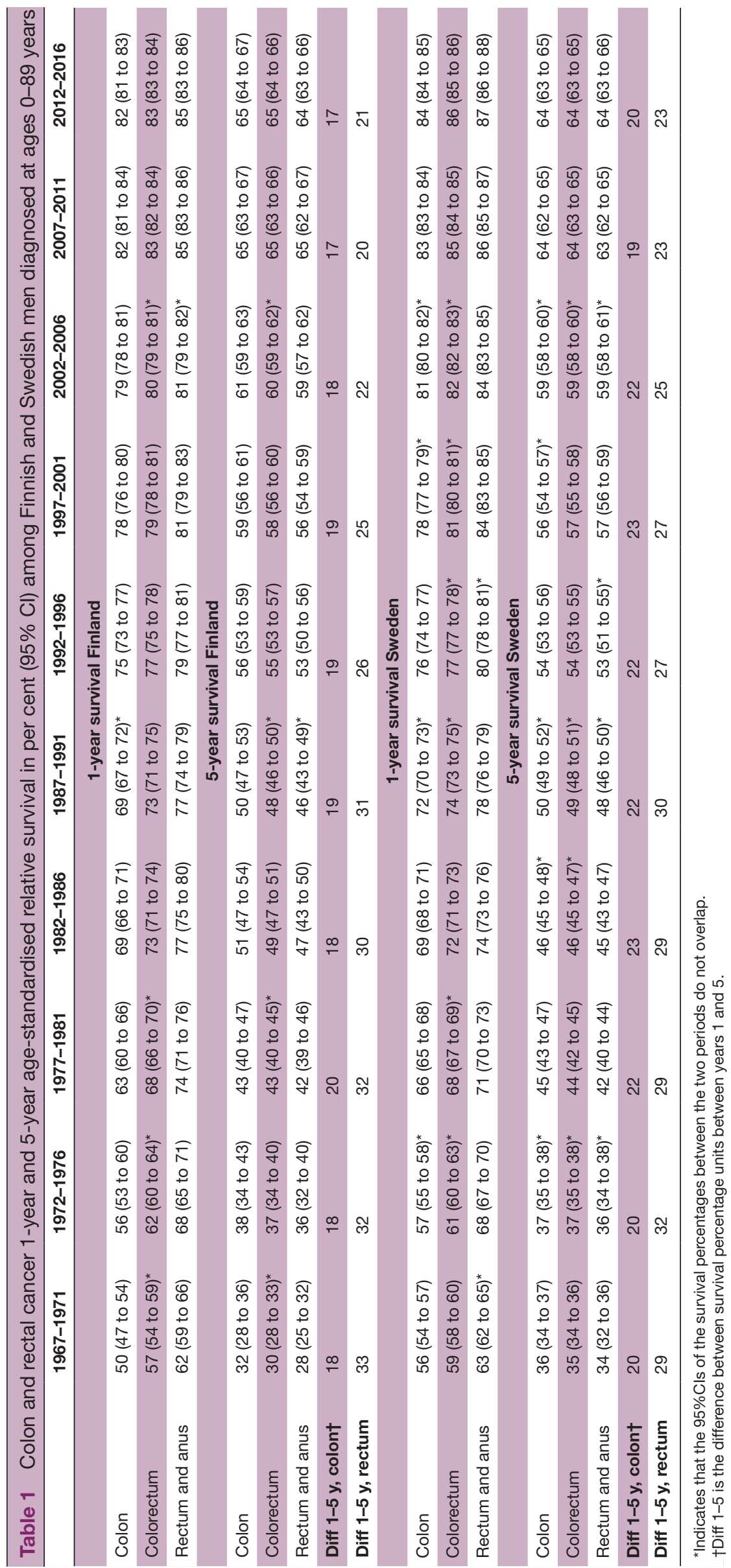




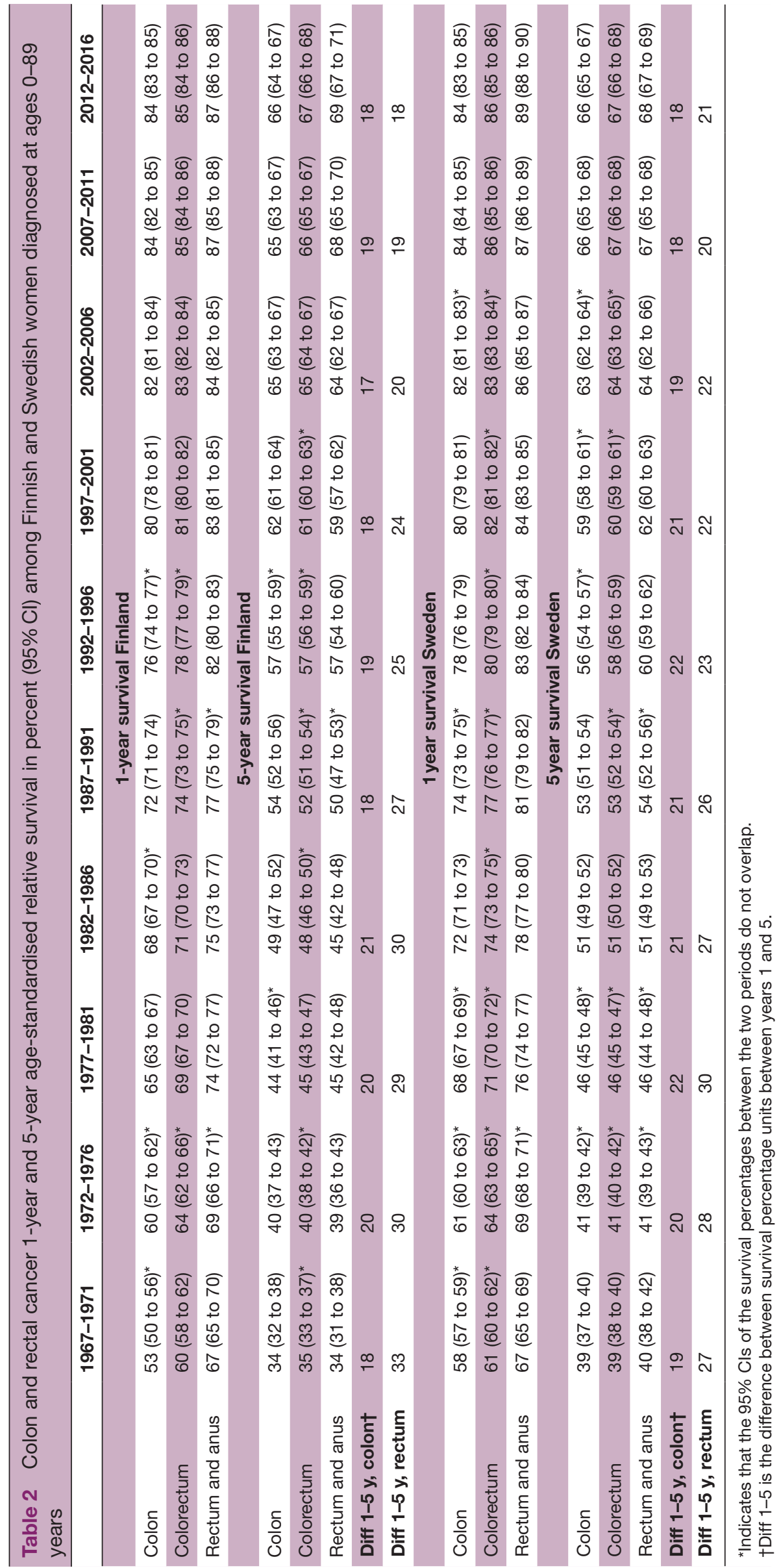



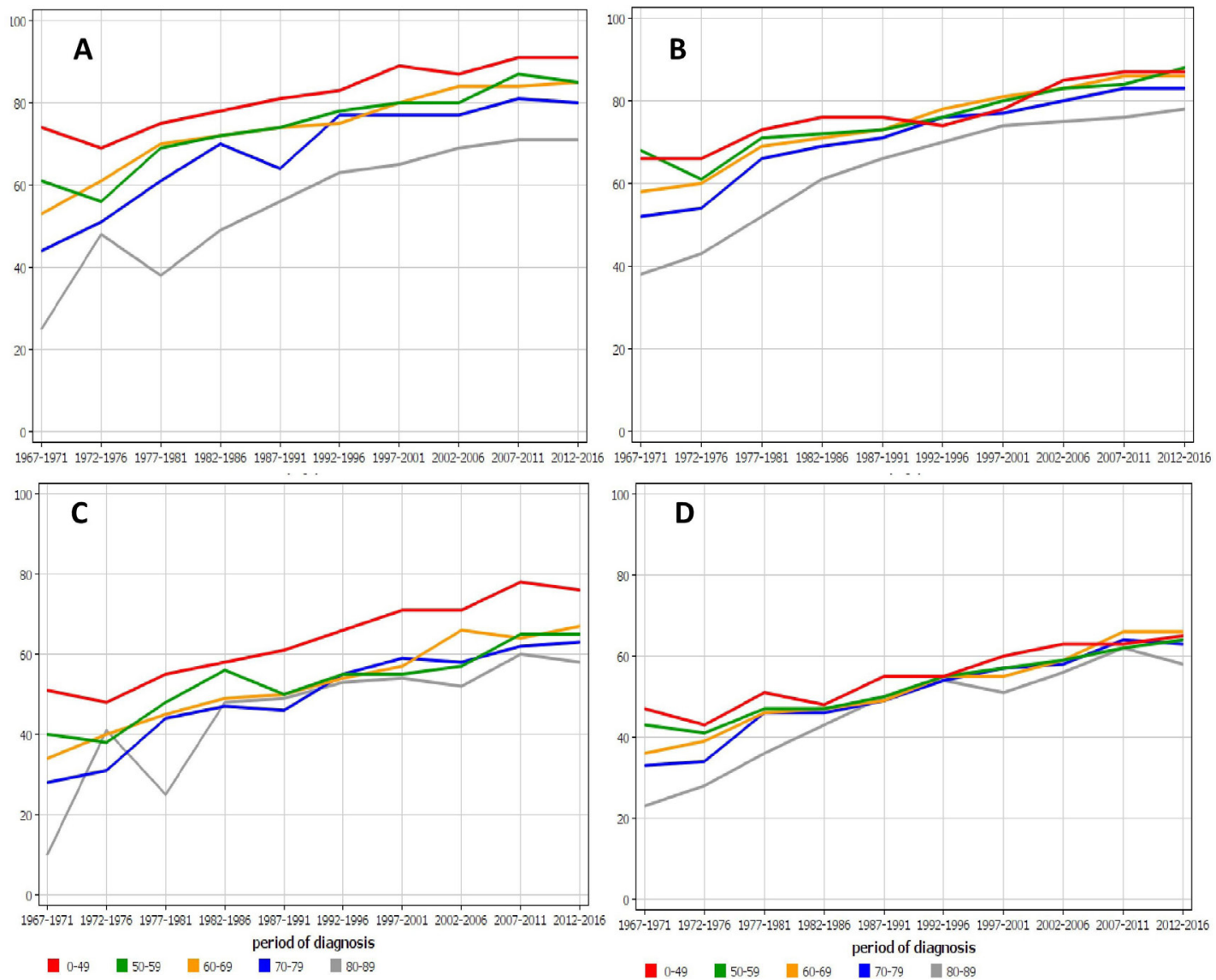

Figure 1 Age-specific 1-year relative survival for colon cancer in (A) Finnish and (B) Swedish men and 5-year survival in the same male populations (C, D). For A and B, all data points for the youngest and oldest age groups are outside the $95 \% \mathrm{Cl}$ limits of all colon cancer survival (cf. table 1); the exceptions are the Swedish youngest age group data points between 1992 and 2001. For C, all data points for the youngest age group are outside the $95 \% \mathrm{Cl}$ limits of all colon cancer survival.

2016 (online supplemental table 1). Finnish male colon cancers numbered 24851 (median age at diagnosis 71 years) compared with 31347 female colon cancers (73 years); the related numbers for Sweden were 73467 (72 years) and 78586 (74 years). Rectal and anal cancers numbered 19889 (69 years) among Finnish men and 17924 (72 years) among women; the Swedish numbers were 49231 ( 71 years) and 38581 (72 years).

Incidence and mortality rates in colon and rectal (and anal) cancers in Finnish and Swedish men and women are shown in online supplemental figure 1. For colon cancer, the trends were quite similar for men and women, higher incidence for Sweden compared with Finland, and continuously increasing; mortality was declining since about 1973 . For male rectal cancer, the incidence rate was modestly increasing while for women it was stable after 1980. Mortality rate has been declining with an equal rate for Finland and Sweden.

Relative 1-year and 5-year survival rates for colon, CRC and rectal cancers for Finnish and Swedish men are shown in table 1 . The male 1-year survival for colon cancer improved constantly, from 50\% (1967-1971) to $82 \%$ (2012-2016) for Finnish men and from $56 \%$ to $84 \%$ for Swedish men. In Finland, the 1-year survival in rectal cancer increased from $62 \%$ to $85 \%$, compared for the increase from $63 \%$ to $87 \%$ in Sweden. The male 5-year survival in Finnish colon cancer increased from $32 \%$ in $1967-1971$ to $65 \%$ in $2012-206$; the comparable increase in Sweden was from $36 \%$ to $64 \%$. For Finnish rectal cancer the increase was from $28 \%$ to $64 \%$ compared with the Swedish one from $34 \%$ to $64 \%$. Of note, not a single survival percentage was improved in Finland between the last two periods. The survival data are plotted in online supplemental figure 2 (A, 1-year survival and B, 5-year survival; the related $95 \%$ CIs are shown in table 1) illustrating the catch-up of colon cancer with rectal cancer in the 1 year survival and almost superimposable increase for colon and rectal cancer in both countries for the 5 -year survival. The both sets of graphs were curvilinear; however, the 5-year survival curves only weakly deviated from linearity.

In table 1 , the stars between the periods indicate a significant increase in survival (ie, 95\% CIs were nonoverlapping). Because statistical significance depends on the sample size, it is instructive to look at the stars for CRC. More significant changes were found in the early period than later, and no single significant change took place between the two last periods.

Table 1 shows also the difference between 1-year and 5 -year survival in per cent units (\% units). In Finland, the 

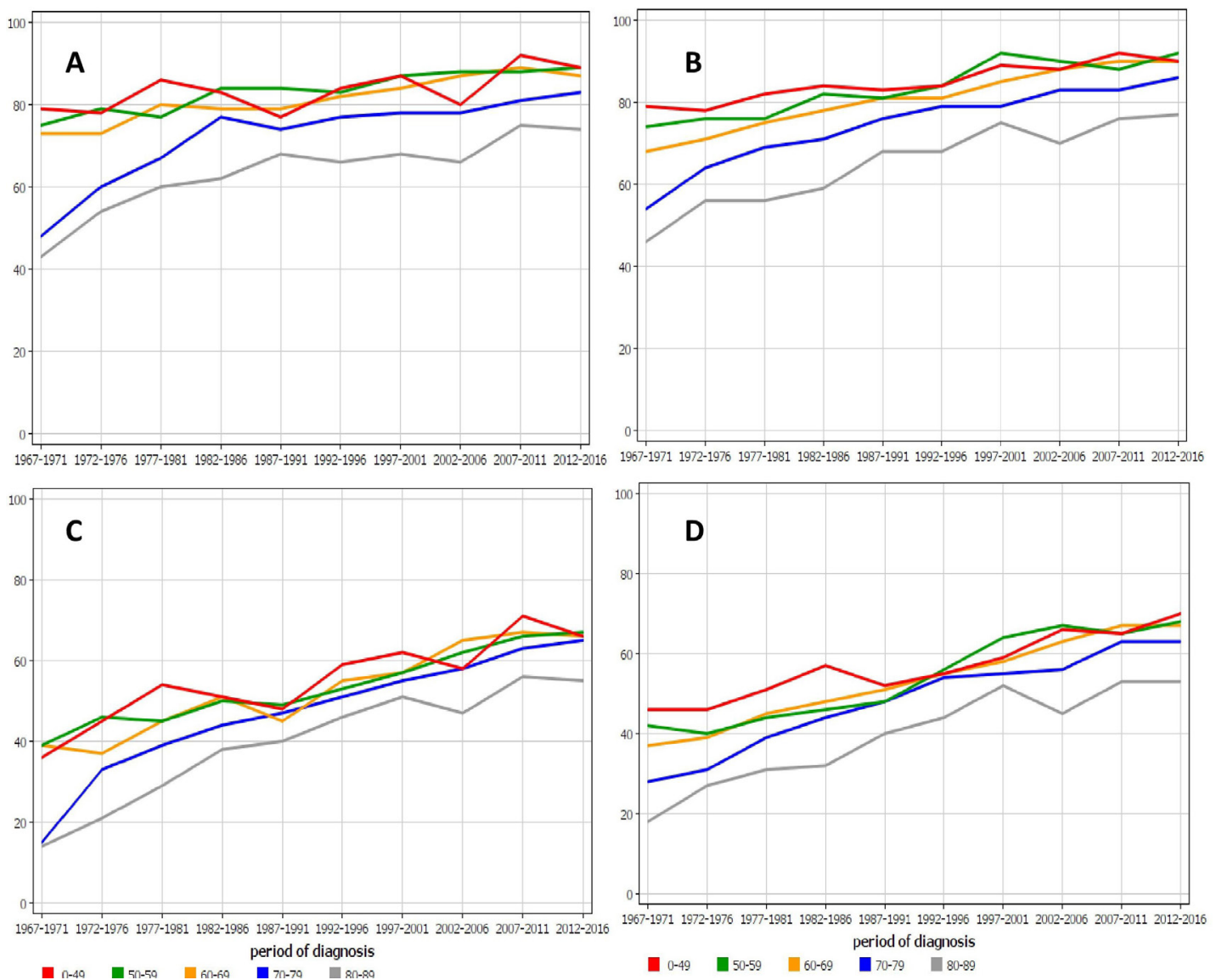

Figure 2 Age-specific 1-year relative survival for rectal (and anal) cancer in (A) Finnish and (B) Swedish men and 5-year survival in the same male populations (C, D). For $A$ and $B$, all data points for the youngest and oldest age groups are outside the $95 \% \mathrm{Cl}$ limits of all rectal cancer survival (cf. table 1); the exception is the Finnish youngest age group. For $\mathrm{C}$ and $\mathrm{D}$, all data points for the oldest age group are outside the $95 \% \mathrm{Cl}$ limits of all rectal cancer survival.

difference in colon cancer was initially $18 \%$ units, then increasing to $20 \%$ units and declining to $17 \%$ units in the last period. For rectal cancer, the largest difference of $33 \%$ units was in the first period and it declined to $21 \%$ units. For Sweden, most of the values were somewhat higher than those for Finland.

Table 2 shows the development in female colon, CRC and rectal cancers. The changes are consistent with the male improvement but at almost every period the female survival is a few $\%$ points above the male survival. The exception was the Swedish 1-year survival for colon cancer for which the final $84 \%$ was equal for men and women. The survival data are plotted in online supplemental figure 3 (A, 1-year survival and B, 5-year survival; the related $95 \%$ CIs are shown in table 2) illustrating the somewhat higher 1-year survival for rectal than colon cancer with a narrowing margin; the 5-year survival graphs are practically superimposable. Also the female graphs are curvilinear.

According to table 2, the difference between 1-year and 5 -year survival in Finland for colon cancer was initially $18 \%$ units, then increasing to $21 \%$ units and declining to $18 \%$ units in the last period. For rectal, the largest difference of $33 \%$ units was in the first period and it declined to $18 \%$ units. For Sweden, the differences between 1-year and 5-year survival in colon cancer resembled the Finnish values but for rectal cancer the final difference of $21 \%$ units was higher than that in Finland.

The periodic 1-year and 5-year survival rates for male and female colon and rectal cancers in online supplemental figure 4 illustrate the point about approximately similar differences between 1-year and 5-year survival for colon cancer and periodic narrowing of the differences for rectal cancer.

Age-specific 1-year relative survival for colon cancer in Finnish (figure 1A) and Swedish (figure 1B) men showed that young men survived well and only the oldest age group, $80-89$ years, experienced markedly poorer survival that the younger ones but the gap narrowed with time. The 5-year survival was most favourable for patients diagnosed before age 50 years in Finland (C) while for the older patients survival was almost equal; in Sweden (D) there was hardly any difference between the age groups.

The age-specific survival for male rectal (and anal) cancer in Finland and in Sweden is shown in figure 2. The two oldest age groups deviated from the younger patients in both countries, but even though the gap narrowed with time, the oldest age group lagged behind; yet, the two oldest groups appeared to have the most favourable survival improvement. 

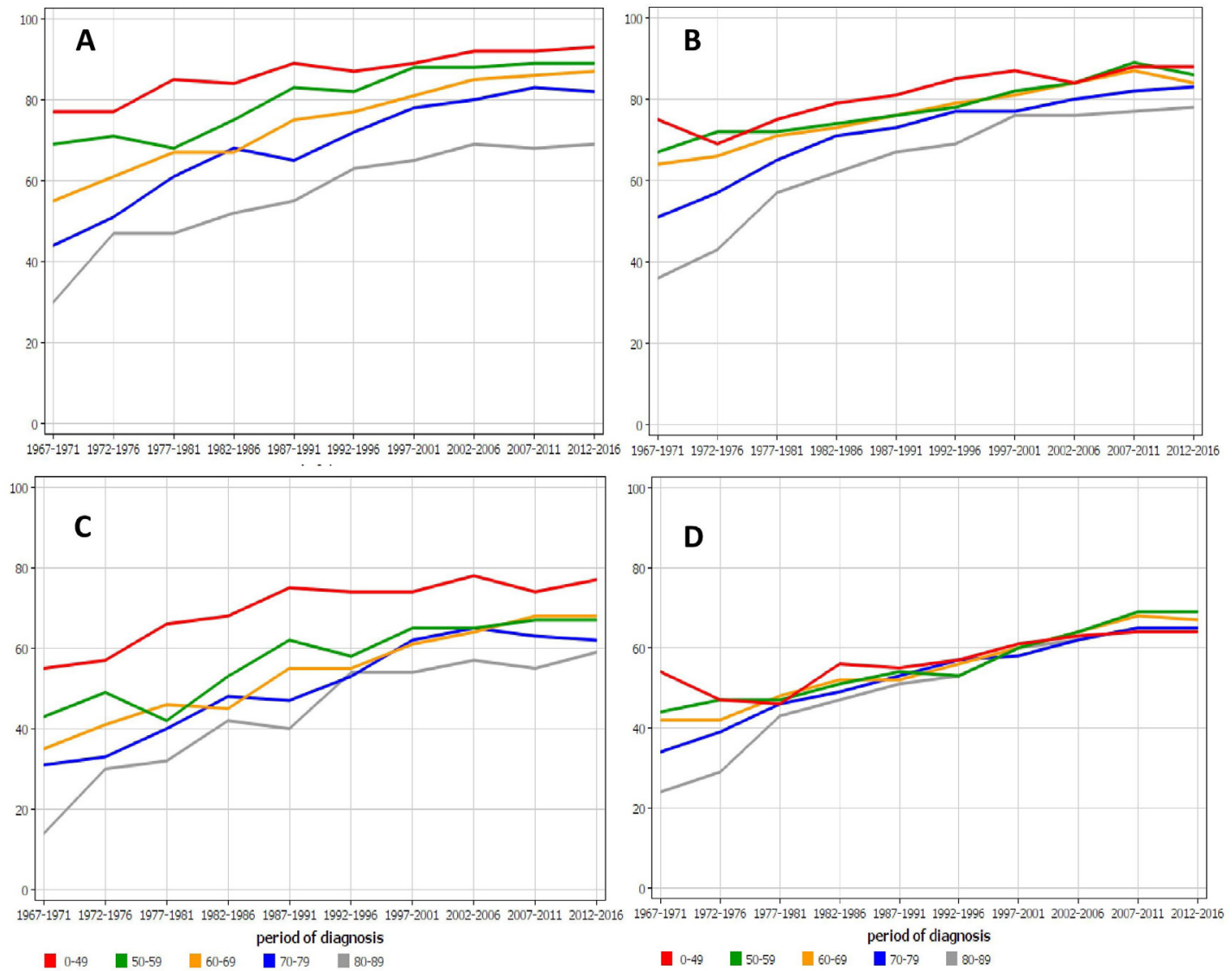

Figure 3 Age-specific 1-year relative survival for colon cancer in (A) Finnish and (B) Swedish women and 5-year survival in the same female populations (C, D). For A, B and C, all data points for the youngest and oldest age groups are outside the $95 \% \mathrm{Cl}$ limits of all colon cancer survival (cf. table 2).

The female results for survival in colon cancer are shown in figure 3. The differences between the age groups were very large for Finnish 1-year and 5-year survival (A and C), and the oldest age group was not able to catch up. While Swedish 1-year survival (B) deviated between the age groups, but 5-year survival rates were remarkably uniform from the 1970s onward.

Age-specific 1-year relative survival for rectal (and anal) cancer in Finnish (figure 4A) and Swedish (figure 4B) women and 5year survival in the same female populations $(\mathrm{C}$ and $\mathrm{D})$ showed very large differences between the age groups and these remained to the end of follow-up.

\section{DISCUSSION}

Success in cancer control is measured by improvements in survival but a proper interpretation of survival data requires background data on incidence and mortality rates. ${ }^{1}$ The incidence rate of colon cancer in Finnish and Swedish men and women has continuously risen, and among Finns at a remarkable rate. The present ecological study is not able to point out the reasons for such increases but some risk factors of colon cancer may have become more prevalent, including increasing body weight, higher consumption of processed meat and lower consumption of whole grain and milk products. ${ }^{22}$ For rectal cancer, the increases in incidence rates were less than for colon cancer. Whatever the reasons might be, comparison of the survival rates between the periods assumes that the underlying disease is comparable. Practically all CRC samples have been histologically verified in the Finnish and the Swedish cancer registries but this is no guarantee against 'stage migration'. ${ }^{16}$

In the early follow-up periods, 1-year survival in rectal cancer was better than for colon cancer but the gap narrowed with time; the results were consistent for men and women in both countries (online supplemental figures 2 and 3). The 5 -year survival curves for the two cancers were superimposable. Both sets of plots were moderately curvilinear implying that the improvements in survival were larger in the early as compared with the late periods. This was also demonstrated in tables 1 and 2 as a larger number of statistically significant increases in CRC survival were observed between the early as compared with the late follow-up periods. These tables also showed that survival for no single cancer type was significantly increased in the last period raising concerns that the positive development has slowed down or stalled.

The survival difference between years 1 and 5 , shown in tables 1 and 2 and in online supplemental figure 4 ), conveys the message that 5-year survival increase in colon cancer was entirely covered by the improvement in 1-year survival, implying that care between years 1 and 5 was not able to save further lives. This may imply that surgery with adjuvant therapies has been able to contribute to 1-year survival but 

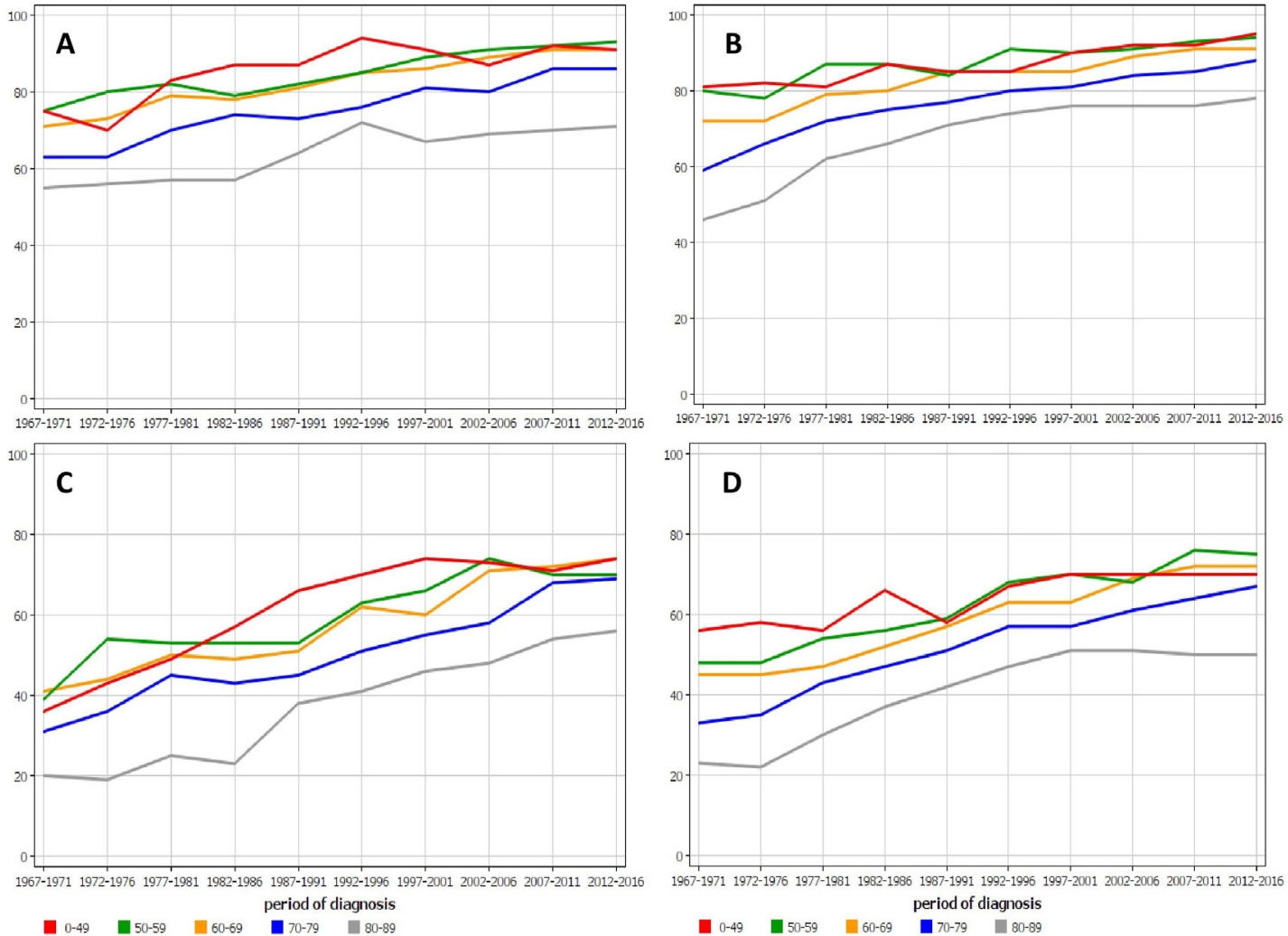

Figure 4 Age-specific 1-year relative survival for rectal (and anal) cancer in (A) Finnish and (B) Swedish women and 5-year survival in the same female populations (C, D). For all panels, all data points for the youngest and oldest age groups are outside the $95 \% \mathrm{Cl}$ limits of all rectal cancer survival (cf. table 2); the exception is the Finnish youngest age group.

chemotherapy or other therapies for metastatic colon cancer have not improved 5-year survival beyond what is achieved with adjuvant therapy. This does not exclude the possibility that newer drug regimens improve survival at time points between 1 and 5 years, as demonstrated in clinical trials. ${ }^{23}$

For rectal cancer, the development was far more optimistic; for Finland, there was a major improvement in survival after year 1, starting from the late 1980s, while in Sweden the trend started earlier but was weaker. Improvements in surgical procedures, such as total mesorectal excision, and wide use of preoperative chemoradiotherapy have been associated with favourable survival in rectal cancer. ${ }^{24-27}$

The age-specific survival for colon cancer showed a positive development for all age groups, and the early lag for survival in the oldest age group almost disappeared towards the end of the follow-up period and practically disappeared in the 5-year survival. Curiously, Finnish patients with colon cancer below age 50 survived very well up to 5 years. Survival in rectal cancer showed large age group specific differences which narrowed over time but the oldest age group clearly lagged behind the others.

One interpretation of these data is that newer treatment regimens have their biggest impact when used as adjuvant therapies. Patients surviving 1 year include patients that were cured, and those that are alive with advanced disease, while 5 -year survival mostly indicates cure rates, as few patients with metastatic disease survive 5 years despite improvements in therapy. Therefore, comparing the difference between 1-year and 5-year survival provides interesting insight into where newer therapies and earlier detection are most useful with regard to survival. In colon cancer, the difference between 1-year and 5-year survival has remained constant over decades, while in rectal cancer it has decreased, indicating a relative increase in the proportion of patients cured. These findings are compatible with bigger improvements in curative treatment in rectal versus colon cancer. One possible explanation is radiation therapy, which is used widely in rectal cancer, with or without concurrent chemotherapy, but not in colon cancer.

The strengths of the study are that we have data from two countries with practically free medical care offered to the population at large, covered by nationwide cancer registries of high quality. Such circumstances are commensurate with the concept of 'real world' experience. The weaknesses are that the data are ecological and no individual level treatment or care data were available. Lack of stage data in the Nordcan database does not allow inclusion of this variable which is an important predictor of survival. ${ }^{28}$ It is generally assumed that the Finnish and Swedish treatment guidelines for CRC are principally similar and largely follow the European guidelines. ${ }^{29}$ However, in the early period, Sweden probably adopted novel therapeutic introductions earlier than Finland. Finally, we are unable to know when and to what extent the therapeutic improvement penetrated the nationwide care practice, with the exception of the reports from the Swedish Colorectal Cancer Registry. ${ }^{30-32}$

Our results show, in agreement with a wealth of the global and local literature, that the relative survival in CRC 
has increased in Finland and in Sweden during the past 50 years. $^{6-8} 1433$ Yet some caution is warranted about the magnitude because of the rising incidence trends. The steady increase in survival implies that the trend cannot be ascribed to any single major change in care but rather to multiple positive changes taking place over time. For colon cancer, the main improvement was in 1-year survival while the period from 1 to 5 years did not contribute, opposite to rectal cancer for which even the survival between years 1 and 5 improved after around year 1980. Yet, in rectal cancer survival for the oldest patients lagged far behold the younger age groups. The analysis pointed out a concern that the overall positive development in survival has been most slow in the last period.

\section{Contributors All authors have contributed to this paper.}

Funding Supported by the European Union's Horizon 2020 research and innovation programme, grant No 856620 (Chaperon), Jane and Aatos Erkko Foundation, Sigrid Juselius Foundation, Finnish Cancer Organisations, University of Helsinki, Helsinki University Central Hospital, Novo Nordisk Foundation, Päivikki and Sakari Sohlberg Foundation.

Competing interests $\mathrm{AH}$ is shareholder in Targovax ASA. AH is employee and shareholder in TILT Biotherapeutics Ltd.

\section{Patient consent for publication Not required.}

Provenance and peer review Not commissioned; externally peer reviewed.

Data availability statement Data are available in a public, open access repository. Publicly available data were used from Nordcan.

Supplemental material This content has been supplied by the author(s). It has not been vetted by BMJ Publishing Group Limited (BMJ) and may not have been peer-reviewed. Any opinions or recommendations discussed are solely those of the author(s) and are not endorsed by BMJ. BMJ disclaims all liability and responsibility arising from any reliance placed on the content. Where the content includes any translated material, BMJ does not warrant the accuracy and reliability of the translations (including but not limited to local regulations, clinical guidelines, terminology, drug names and drug dosages), and is not responsible for any error and/or omissions arising from translation and adaptation or otherwise.

Open access This is an open access article distributed in accordance with the Creative Commons Attribution Non Commercial (CC BY-NC 4.0) license, which permits others to distribute, remix, adapt, build upon this work non-commercially, and license their derivative works on different terms, provided the original work is properly cited, appropriate credit is given, any changes made indicated, and the use is non-commercial. See: http://creativecommons.org/licenses/by-nc/4.0/.

ORCID iD

Kari Hemminki http://orcid.org/0000-0002-2769-3316

\section{REFERENCES}

1 Ellis L, Woods LM, Estève J, et al. Cancer incidence, survival and mortality: explaining the concepts. Int J Cancer 2014;135:1774-82.

2 Allemani C, Weir HK, Carreira H, et al. Global surveillance of cancer survival 1995-2009: analysis of individual data for 25,676,887 patients from 279 population-based registries in 67 countries (CONCORD-2). Lancet 2015;385:977-1010.

3 Diehl V, Thomas RK, Re D. Part II: Hodgkin's lymphoma--diagnosis and treatment. Lancet Oncol 2004;5:19-26.

4 Pui C-H, Nichols KE, Yang JJ. Somatic and germline genomics in paediatric acute lymphoblastic leukaemia. Nat Rev Clin Oncol 2019;16:227-40

5 Hanna N, Einhorn LH. Testicular cancer: a reflection on 50 years of discovery. J Clin Oncol 2014;32:3085-92.

6 De Angelis R, Sant M, Coleman MP, et al. Cancer survival in Europe 1999-2007 by country and age: results of EUROCARE--5-a population-based study. Lancet Oncol 2014;15:23-34.

7 Brenner H, Bouvier AM, Foschi R, et al. Progress in colorectal cancer survival in Europe from the late 1980s to the early 21st century: the EUROCARE study. Int J Cancer 2012;131:1649-58.
8 Lundberg FE, Andersson TM-L, Lambe M, et al. Trends in cancer survival in the Nordic countries 1990-2016: the NORDCAN survival studies. Acta Oncol 2020;59:1266-74.

9 Global Burden of Disease Cancer Collaboration, Fitzmaurice C, Abate D, et al. Global, regional, and National cancer incidence, mortality, years of life lost, years lived with disability, and DisabilityAdjusted life-years for 29 cancer groups, 1990 to 2017: a systematic analysis for the global burden of disease study. JAMA Oncol 2019;5:1749-68.

10 Lu X-Q, Li Y, Wang W, et al. International incidence trends in earlyand late-onset colorectal cancer: a population-based study. Int $J$ Colorectal Dis 2020;35:1077-86.

11 Tamas K, Walenkamp AME, de Vries EGE, et al. Rectal and colon cancer: not just a different anatomic site. Cancer Treat Rev 2015;41:671-9.

12 Riihimäki M, Hemminki A, Sundquist J, et al. Patterns of metastasis in colon and rectal cancer. Sci Rep 2016;6:29765.

13 Storm HH, Engholm G, Hakulinen T, et al. Survival of patients diagnosed with cancer in the Nordic countries up to 1999-2003 followed to the end of 2006. A critical overview of the results. Acta Oncol 2010;49:532-44.

14 Wong MCS, Huang J, Lok V, et al. Differences in incidence and mortality trends of colorectal cancer worldwide based on sex, age, and anatomic location. Clin Gastroenterol Hepatol 2021;19:955-66.

15 Engholm G, Ferlay J, Christensen N, et al. NORDCAN--a Nordic tool for cancer information, planning, quality control and research. Acta Oncol 2010;49:725-36.

16 Pukkala E, Engholm G, Højsgaard Schmidt LK, et al. Nordic Cancer Registries - an overview of their procedures and data comparability. Acta Oncol 2018;57:440-55.

$17 \mathrm{Ji} \mathrm{J}$, Sundquist K, Sundquist J, et al. Comparability of cancer identification among death registry, cancer registry and hospital discharge registry. Int J Cancer 2012;131:2085-93.

18 Centre for Epidemiology. Cancer incidence in Sweden 2012. Stockholm: The National Board of Health and Welfare, 2013.

19 Storm HH, Klint A, Tryggvadóttir L, et al. Trends in the survival of patients diagnosed with malignant neoplasms of lymphoid, haematopoietic, and related tissue in the Nordic countries 19642003 followed up to the end of 2006. Acta Oncol 2010;49:694-712.

20 Engholm G, Gislum M, Bray F, et al. Trends in the survival of patients diagnosed with cancer in the Nordic countries 1964-2003 followed up to the end of 2006. material and methods. Acta Oncol 2010;49:545-60.

21 Brenner H, Rachet B. Hybrid analysis for up-to-date long-term survival rates in cancer registries with delayed recording of incident cases. Eur J Cancer 2004;40:2494-501.

22 Kuipers EJ, Grady WM, Lieberman D, et al. Colorectal cancer. Nat Rev Dis Primers 2015;1:15065.

23 DeStefanis RA, Kratz JD, Emmerich PB, et al. Targeted therapy in metastatic colorectal cancer: current standards and novel agents in review. Curr Colorectal Cancer Rep 2019;15:61-9.

24 Babaei M, Jansen L, Balavarca Y, et al. Neoadjuvant therapy in recta cancer patients with clinical stage II to III across European countries: variations and outcomes. Clin Colorectal Cancer 2018:17:e129-42.

25 Glimelius B, Holm T, Blomqvist L. Chemotherapy in addition to preoperative radiotherapy in locally advanced rectal cancer - a systematic overview. Rev Recent Clin Trials 2008;3:204-11.

26 Birgisson H, Talbäck M, Gunnarsson U, et al. Improved survival in cancer of the colon and rectum in Sweden. Eur J Surg Oncol 2005;31:845-53.

27 Dahlberg M, Påhlman L, Bergström R, et al. Improved survival in patients with rectal cancer: a population-based register study. $\mathrm{Br} \mathrm{J}$ Surg 1998;85:515-20.

28 Qaderi SM, Dickman PW, de Wilt JHW, et al. Conditional survival and cure of patients with colon or rectal cancer: a population-based study. J Natl Compr Canc Netw 2020;18:1230-7.

29 van de Velde $\mathrm{CJH}$, Aristei C, Boelens PG, et al. Eurecca colorectal: multidisciplinary mission statement on better care for patients with colon and rectal cancer in Europe. Eur J Cancer 2013;49:2784-90.

30 Kodeda K, Johansson R, Zar N, et al. Time trends, improvements and national auditing of rectal cancer management over an 18-year period. Colorectal Dis 2015;17:0168-79.

31 Kodeda K, Nathanaelsson L, Jung B, et al. Population-based data from the Swedish colon cancer registry. Br J Surg 2013;100:1100-7.

32 Lindskog EB, Gunnarsdóttir Katrín Ásta, Derwinger K, et al. A population-based cohort study on adherence to practice guidelines for adjuvant chemotherapy in colorectal cancer. BMC Cancer 2014;14:948.

33 Sun $\mathrm{M}$, Wang $\mathrm{Y}$, Sundquist $\mathrm{J}$, et al. Temporal trends of sex disparity in incidence and survival of colorectal cancer: variations by anatomical site and age at diagnosis. Clin Epidemiol 2020;12:73-81. 